\title{
PENGAJARAN DAN PEMBELAJARAN MASS-MEDIA DI IPTA THAILAND: SATU PELUANG KERJAYA BAGI MAHASISWA
} \author{
A Career Opportunity for Students \\ Djusmalinar
djusmalinar.d@psu.ac.th/ndjus@hotmail.com \\ Faculty of Humanities and Social Science \\ Eastern Languages, Malay Section \\ Prince of Songkla University \\ Pattani Campus
}

The Teaching and Learning of Mass Media in Public Universities in Thailand:

\begin{abstract}
ABSTRAK
Pengajaran Bahasa Melayu (BM) di Institusi Pengajian Tinggi Awam (IPTA) di Selatan Thailand telah bermula semenjak tahun 1982, khasnya di University Prince of Songkla. Berdasarkan kurikulum yang dirancangkan, pada peringkat awal, para graduan hanya disiapkan untuk berkhidmat dalam bidang pendidikan sebagai guru mata pelajaran BM. Semenjak tahun 2007, objektif kurikulum tersebut menerima perubahan berdasarkan perkembangan teknologi maklumat dengan menyenaraikan beberapa kursus yang ada kaitan dengan mass-media atau media massa. Kajian ini difokuskan pada kursus mass-media kerana dalam tempoh sepuluh tahun pertama (2007-2017) dilaksanakan, didapati ramai pelajar yang berminat mengikuti kursus ini. Hasil pembelajaran dan pengajaran kursus juga telah dinilai oleh pelajar sendiri melalui sistem dalam talian yang disediakan melalui https://mis1.pn.psu.ac.th/neomis/eval/eval_main.php?sp_lec=yes. Hasil penilaian tersebut seterusnya dijadikan data kajian untuk merumuskan pembelajaran BM yang berkesan di peringkat IPTA, Thailand. Dapatan kajian menunjukkan bahawa medium yang digunakan pelajar mempengaruhi pembelajaran dan pengajaran. Kaedah praktikal atau latihan kerja dan aras pembelajaran yang berkesan memberi peluang kepada pelajar untuk berani turun ke lapangan menghadapi cabaran dunia nyata dalam beberapa jenis kerjaya; sama ada sebagai juruhebah, wartawan atau pemberita mahupun sebagai penterjemah dan seumpamanya.
\end{abstract}

Kata kunci: mass-media; aras pengajaran; praktikal; kerjaya; Bahasa Melayu.

\begin{abstract}
Teaching Bahasa Melayu (BM) in Institutions of Higher Learning (IPTA) in Southern Thailand has started since 1982, in particular in Prince of Songkla Universiti. Based on the curriculum planned, at an early stage, the graduates are prepared for a career in education as a Bahasa Malayu teacher. Since 2007, the objective of the curriculum is to accept changes based on the development of information technology by listing numbers of courses related to the mass-media. This study focused on mass-media courses since for the first ten years (2007-2017) of its imeplementation; it is found that many students are interested in attending this course. Learning outcomes and teaching courses have been evaluated by the students themselves through the online system provided by https://mis1.pn.psu.ac.th/neomis/eval/eval_main.php?sp_lec=yes. Result of this evaluation were used as data for the survey to formulate an effective BM learning at university level in Thailand. The results showed that the medium used influences student learning and teaching. Practical or vocational training methods and effective level of learning provide opportunities for students to face the challenges of the real world in careers such as broadcaster, journalist, reporter, or translator and etc.
\end{abstract}

Keywords: mass-media; level of learning; practical; career and Bahasa Melayu. 


\section{PENGENALAN}

Prince of Songkla Universiti (PSU), kampus Pattani merupakan salah sebuah Institusi Pengajian Tinggi Awam (IPTA) yang menawarkan kursus bahasa Melayu yang pertama di Thailand sebagai mata kuliah yang mempunyai status yang sama dengan mata kuliah lain. Kursus ini dilaksanakan di bawah Jabatan BahasaBahasa Timur, Fakulti Kemanusiaan dan Kemasyarakatan. Pengajaran bahasa Melayu di PSU ini telah bermula semenjak lebih 30 tahun yang lalu.

Pada tahun 1982 kursus bahasa Melayu mula dibuka dengan status sebagai kursus pilihan bebas atau dikenali dengan kursus elektif. Kursus ini boleh diambil oleh mahasiswa daripada pelbagai fakulti. Semenjak tahun 1985 statusnya meningkat menjadi kursus minor. Pada tahun 2000, barulah kursus ini ditingkatkan menjadi kursus major.

Ini bererti, bahasa Melayu telah menjadi satu jurusan yang dapat disamakan dengan jurusan-jurusan lain di PSU; seperti jurusan bahasa Thai dan bahasa-bahasa asing yang lain seperti bahasa Inggeris, bahasa Korea, bahasa Jepun, bahasa Cina, bahasa Arab, bahasa German dan bahasa Perancis.

Jurusan Bahasa Melayu semakin mendapat sambutan masyarakat umumnya dan kerajaan khasnya dengan wujudnya kesepakatan Komuniti ASEAN yang menjadikan bahasa Melayu sebagai bahasa pengantar ilmu dan juga sebagai lingua franca bagi masyarakat di rantau ini.

Pengajaran dan Pembelajaran Bahasa Melayu di Institusi Pengajian Tinggi Awam Thailand Pengajaran dan pembelajaran bahasa Melayu yang dijalankan di IPTA Thailand mesti berdasarkan kurikulum khas yang telah dirancangkan. Dasar perancangan kurikulum itu juga hendaklah berdasarkan visi, misi dan objektif IPTA berkenaan, dan PSU adalah satu daripadanya.

Daripada kurikulum yang telah dirancang, ditetap dan dipersetujui oleh Kementerian Pendidikan itulah kemudiannya dilaksanakan. Pelaksanaan kurikulum ini merupakan tugas dan tanggungjawab setiap pengajar. Dalam kelangsungan pengajaran dan pembelajaran di bilik kuliah, pengajar hendaklah mengajar berpandukan kurikulum yang telah dirancangkan itu. Pengajar dapat memadu dan memodifikasikan cara pengajaran masing-masing ketika pembelajaran berkaitan berlangsung dalam kalangan mahasiswa/i. Hal ini dilakukan supaya pembelajaran yang dijalankan menjadi lebih menarik, tidak membosankan dan dapat mencapai objektif sebagaimana yang dirancangkan dalam kurikulum.

Kurikulum yang dirancangkan 30 tahun lalu mempunyai matlamat hanya untuk menyiapkan mahasiswa menjadi seorang guru, sama ada di sekolah mahupun di IPT. Walau bagaimanapun, hal itu pada hari ini sudah berbeza. Kurikulum yang dijalankan hari ini harus berdasarkan kehendak dan perubahan zaman serta perkembangan teknologi maklumat. Kurikulum seumpama itulah telah digunakan semenjak tahun 2007.

Kurikulum 2007 ini mempunyai matlamat untuk memberi peluang kerjaya kepada para mahasiswa selepas menjadi graduan. Mereka para graduan, diharapkan dapat menjadi juruhebah, pemberita atau wartawan, penterjemah dan seumpamanya. Salah satu kursus yang ditawarkan dan ramai diminati mahasiswa adalah kursus Mass-Media yang meliputi media cetak dan media audio visual.

\section{KAJIAN LEPAS}

Kajian mengenai pengajaran dan pembelajaran bahasa Melayu di IPTA Thailand belum banyak dilakukan. Hal ini disebabkan pengajaran dan pembelajaran yang dilaksanakan di beberapa IPTA Thailand masih banyak yang berstatus sebagai kursus pilihan atau minor. Manakala pengajarannya masih menggunakan aras rendah, khasnya untuk kursus Malay I, Malay II, Malay III, Malay IV, Malay V, Malay Conversation I, Malay Conversation II, Malay Comunicative I dan Malay Communicative II. Sebagaimana diketahui, sebelum pelaksanaan kurikulum 2007, penggunaan bahasa Melayu dalam kalangan mahasiswa IPTA di Selatan Thailand amat lemah walaupun sebelum ke IPTA mereka sudah pun mempelajarinya dari sekolah rendah hingga sekolah menengah. 
Sebagaimana yang dinyatakan dalam kajian Ab. Razak Ab. Karim dan Mohd. Saiful Haq bin Hussin (2011) bahawa tahap penguasaan bahasa Melayu dalam kalangan mahasiswa Melayu warga negara Thailand yang melanjutkan pengajian di peringkat IPT di Malaysia; khasnya di Akademi Pengajian Melayu, Universiti Malaya didapati sangat lemah. Menurut hasil dapatan mereka, pendekatan, kaedah dan teknik yang digunakan oleh guru-guru semasa mengajar bahasa Melayu tidak sistematik. Guru dan pelajar juga menghadapi kekangan daripada dasar negara yang berbahasa Thailand sehingga menjadikan pengajaran dan pembelajaran begitu bermasalah.

Kajian yang berfokuskan permasalah bahasa dalam kalangan mahasiswa di IPT Thailand telah dilakukan juga oleh Djusmalinar di bawah tajuk "Praktikal Bahasa: Pembelajaran Bahasa Melayu di IPTA Selatan Thailand" dalam jurnal Artikulasi (2013). Menurutnya, pembelajaran bahasa Melayu lebih berkesan kepada mahasiswa di IPTA Thailand, khasnya di PSU melalui praktikal langsung, terutama untuk beberapa mata kuliah yang ditawarkan seperti Malay for Tourism, Malay in Radio and Television, dan Malay Creative Writing. Kerja lapangan atau praktikal secara langsung merupakan aktiviti pembelajaran yang bertujuan untuk melibatkan pelajar ketika pembelajaran mata kuliah berkaitan berlangsung. Misalnya sewaktu di lapangan, pelajar terpaksa menghadapi dan mengalami pelbagai situasi dan kerenah, khasnya ketika sedang memandu pelancong, atau ketika melaporkan berita dan seumpamanya.

Selari dengan kerja lapangan atau praktikal itu, kajian berkaitan masalah bahasa seterusnya telah dilakukan oleh Alizah Lambri dan Zamri Mahamod (2015) dalam jurnal Pendeta dengan tajuk "Pelaksanaan Aktiviti Pembelajaran Berasaskan Masalah dalam Proses Pengajaran dan Pembelajaran Bahasa Melayu". Kerja lapangan seumpama itu di peringkat universiti sangat diminati para mahasiswa kerana ia amat menyeronokkan. Pembelajaran berasaskan masalah adalah salah satu daripada strategi pembelajaran kerana berpusatkan pelajar. Melalui pembelajaran tersebut, para mahasiswa dapat membuat kumpulan, dapat mengenal pasti masalah, dan dapat menjana idea serta dapat merancang pelan tindakan.

Hasil pembelajaran menjadi lebih berkesan adalah disebabkan adanya semangat kerjasama sesama mahasiswa ketika proses pembelajaran itu berlangsung. Hal ini dinyatakan oleh Norul Haida Reduzan (2012) dalam makalahnya dalam jurnal Pendeta yang bertajuk "Pembelajaran secara Koperatif dalam Kelas Bahasa Melayu". Katanya, pembelajaran secara koperatif berupaya mengatasi jurang pemisah antara jantina, usia dan pemikiran mahasiswa.

\section{PENYATAAN MASALAH}

Berdasarkan pengenalan dan kajian-kajian lepas seperti dinyatakan di atas, pengkaji berpendapat bahawa kajian ini perlu diteruskan untuk mendapatkan pendekatan, kaedah dan sistem pengajaran dan pembelajaran bahasa Melayu yang lebih berkesan terutama dalam kalangan mahasiswa peringkat IPTA di negara Thailand, khasnya di PSU kampus Pattani. Hal ini didorong oleh matlamat sebagaimana yang dihuraikan dalam kurikulum; sesuai dengan era teknologi maklumat dan menghendaki supaya mata kuliah yang ditawarkan itu dapat memberi gambaran langsung mengenai bentuk dan jenis-jenis kerjaya kepada mahasiswa.

Selain itu, aktiviti-aktiviti pembelajaran, khasnya mata kuliah mass-media harus menggalakkan penglibatan langsung mahasiswa dalam pengajaran. Penglibatan langsung mahasiswa kepada perkara-perkara yang benar-benar berlaku; seperti tentang kehidupan sebenar dalam kerjaya sebagai seorang wartawan atau pemberita, sebagai seorang juruhebah atau pembaca berita di radio mahupun di televisyen. Dua jenis kerjaya ini adalah antara kerjaya yang sangat diminati golongan remaja hari ini. Oleh itu, kreativiti seorang pensyarah amat diperlukan supaya dapat menggunakan pendekatan yang fleksibel dan dapat menarik minat mahasiswa mengikuti mata kuliah yang dijalankan.

\section{OBJEKTIF KAJIAN}

Kajian ini dijalankan dengan tujuan untuk mencapai objektif seperti berikut: 
1. Mengenal pasti medium yang berkesan dalam pengajaran dan pembelajaran mass-media berbahasa Melayu di peringkat IPTA Thailand.

2. Mengenal pasti kaedah yang berkesan dalam pengajaran dan pembelajaran mass-media berbahasa Melayu di peringkat IPTA.

3. Mengenal pasti aras yang baik dan berkesan yang digunakan dalam pengajaran dan pembelajaran mass- media berbahasa Melayu.

4. Mendapat faedah daripada kursus mass-media berbahasa Melayu dan berani menggunakan bahasa Melayu di Negara Thailand yang bahasa Thai sebagai bahasa rasminya.

\section{KAEDAH KAJIAN}

Kajian ini menggunaikan kaedah kualitatif. Metodologi kualitatif merupakan prosedur penyelidikan yang menghasilkan data deskriptif berdasarkan kemahiran penulisan berbentuk skrip dan kemahiran lisan dalam bentuk rakaman audio oleh para mahasiswa. Kaedah yang digunakan dalam kajian ini adalah pemerhatian ke atas tugasan-tugasan mahasiswa. Pertama, mahasiswa dikehendaki membuat laporan secara bertulis sebagai wartawan atau pemberita. Kedua, mahasiswa dikehendaki membuat rakaman dalam bentuk CD ketika siaran secara off-air sebagai juruhebah radio dalam studio. Ketiga, mahasiswa dikehendaki membuat rakaman dalam bentuk VCD ketika membaca berita di studio radio atau di studio televisyen.

Pengkaji menggunakan ketiga-tiga tugasan tersebut sebagai data kajian. Selain daripada itu, pengkaji juga menggunakan hasil penilaian mahasiswa ke atas pensyarah berdasarkan soalan-soalan yang dikemukakan secara online melalui laman sesawang https://mis1.pn.psu.ac.th/neo-mis/eval/eval main.php?sp lec=yes. Penilaian peringkat ini berkaitan soalan-soalan tentang sejauh mana kejayaan pensyarah yang melibatkan tahap keberkesanan penyampaian pengajaran dan pembelajaran kepada mahasiswa selepas mengikuti mata kuliah mass-media ini.

Sebarang data berupa laporan bertulis, CD dan VCD yang pengkaji peroleh daripada mahasiswa adalah menjadi sampel kajian. Dalam tempoh tiga semester; iaitu sesi kedua tahun-tahun 2014, 2015 dan 2016 terdapat sebanyak enam buah CD dan VCD yang dapat dijadikan sampel kajian. Sampel-sampel ini kemudian dianalisis dengan menggunakan instrumen komputer untuk diberi markah kepada mahasiswa.

Seterusnya pengkaji mengkatagorikan maklumat yang diperoleh itu untuk menjawab soalan yang pertama melalui tugasan berupa CD dan VCD. Soalan yang kedua boleh dijawab melalui tugasan dalam bentuk laporan bertulis ketika mahasiswa membuat liputan sesuatu peristiwa. Manakala soalan yang ketiga, boleh dijawab melalui tugasan laporan bertulis, dengan melaporkan berita. Hasil penilaian mahasiswa seterusnya ialah jawapan daripada soalan yang keempat.

\section{DAPATAN KAJIAN}

Berikut ialah hasil dapatan kajian daripada pengajaran dan pembelajaran mass-media berbahasa Melayu di PSU, kampus Pattani:

\section{Medium yang digunakan ialah VCD}

Inovasi dalam pengajaran dan pembelajaran mass-media berbahasa Melayu telah dilakukan dengan bantuan komputer. Melalui alat komputer ini pengajaran dan pembelajaran dapat dikreasikan sehingga menghasilkan multimedia yang berkesan sesuai dengan perkembangan teknologi maklumat. Salah satu daripadanya, pengajaran dan pembelajaran dapat dirakam dalam bentuk VCD. Medium VCD sangat berguna untuk mengetahui apa yang telah diajarkan, bagaimana proses pembelajaran tersebut berlangsung dan apa sahaja tugasan yang telah dihasilkan oleh pelajar.

Hasil rakaman VCD dapat membuktikan pelbagai unsur kesalahan lisan seseorang melalui laporan yang dibuat. Sebarang kesilapan dapat diperbaiki secara serta-merta ketika ditayang melalui kuliah. Selain daripada 
itu, rakaman VCD ini boleh membantu melatih mahasiswa menguasai bahasa Melayu baku atau bahasa Melayu persuratan; lisan dan tulisan secara serentak.

\section{Kaedah: Praktikal}

Pengajaran dan pembelajaran mass-media berbahasa Melayu dalam kalangan mahasiswa bahasa kedua lebih berkesan apabila dilaksanakan melalui pengajaran latihan di lapangan. Melalui latihan praktikal seumpama itu, mereka dapat menguasai empat kemahiran serentak; iaitu kemahiran lisan, kemahiran menulis, kemahiran berfikir dan kemahiran berinovasi. Keempat-empat kemahiran tersebut boleh berlaku secara bertahap dan juga secara serentak.

Sesuatu kemahiran lisan dapat dilihat melalui aktiviti laporan yang disampaikan secara langsung. Kemahiran menulis pula dapat dllihat melalui penyusunan ayat dan seumpamanya yang boleh dibaca melalui penulisan skrip sesebuah laporan yang dibuat. Manakala kemahiran berfikir dapat dilihat melalui pilihan kata; sama ada menepati maksud tentang sesebuah laporan tersebut. Selanjutnya kemahiran berinovasi akan dapat dinilai selepas selesai menyiap dan menyerahkan laporan lengkap dalam bentuk rakaman melalui sebuah VCD.

Kaedah praktikal atau latihan di lapangan lebih berkesan apabila mahasiswa diberikan sesuatu 'masalah' berupa peristiwa yang hendak dilaporkan secara spontan atau on the spot. Peristiwa tersebut boleh sahaja disesuaikan dengan situasi kehidupan mahasiswa dalam persekitaran kampus universiti.

\section{Aras Pengajaran: Aras Menengah}

Aras pengajaran yang berkesan dalam mengendalikan kursus mass-media adalah aras menengah. Penekanan pengajaran dan pembelajaran pada kemahiran lisan selain kemahiran menulis dan berfikir sangat penting. Kemahiran lisan merupakan objektif pertama yang perlu dicapai oleh seseorang yang mempelajari bahasa, sama ada penutur bahasa pertama mahupun penutur bahasa kedua. Selain itu tumpuan dalam kemahiran berkomunikasi di media massa juga diberikan untuk golongan pendengar atau penonton. Hal ini kerana kursus mass-media ini lebih difokuskan kepada penglahiran kerjaya sebagai juruhebah atau pembaca berita di radio atau di televisyen.

Susunan ayat yang digunakan untuk sesebuah berita yang hendak disampaikan adalah struktur kalimat yang sederhana. Perkara ini dilakukan supaya pendengar dan para penonton dapat memahami sebarang berita dan laporan yang disampaikan. Hal ini dilakukan demikian berdasarkan prinsip jurnalistik; iaitu singkat, padat, jelas, sederhana, lancar dan menarik kerana ukuran masyarakat penerima maklumat adalah intelektual minimum.

Sebagai bahan sokongan, terlebih dahulu diberikan contoh kepada para pelajar mengenai bahasa siaran dan laporan radio tempatan supaya tidak berlaku sebarang kesalahan oleh pembaca berita atau pelapor. Salah satu contohnya adalah seperti yang berikut:

/Selame petc pendenga semua/

/Saya Nik Husna sebagai penyia memandu acara ni/

/Saya akan ttemani soudara- soudara semua selama peteni/

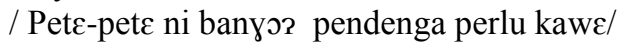

/Saya siap ttmani demo utama bag idreba bas sekolah, dreba kreta borong, dan pekerja yang baru balik kerja/

/Bhaghi nak pese- pese lagu dapat thorosap ditalian 073-368-739/

Teks di atas adalah sebagai contoh gaya bahasa juruhebah sebuah radio tempatan di Patani yang masih menggunakan dialek Melayu Patani. Selain daripada slanga dan dialek Patani, terdapat penggunaan bahasa Melayu pinjaman daripada kosa kata Thailand dan Inggeris. Melihat hal yang demikian, mahasiswa diberikan tugasan untuk mengubahnya menjadi bahasa Melayu persuratan. Hasilnya seperti contoh yang berikut:

\section{Selamat petang pendengar semua.}


"Saya Nik Husna sebagai penyiar acara ini akan menemani saudara-saudara semua selama dua jam. Petang-petang biasanya ramai pendengar yang memerlukan kawan. Saya siap menemani perjalanan anda, seperti pemandu bas sekolah, kereta sewa, atau pekerja yang baru pulang kerja. Bagi yang hendak memesan lagu, boleh hubungi telefon di nombor 073-368-739."

Selain memberikan tugasan membetulkan kesalahan tatabahasa dalam teks, mereka juga diberikan tugas untuk membacakan berita atau melaporkan berita sebagai pemberita atau pembaca berita di radio. Maklumat yang dibacakan oleh pembaca berita dan pelapor berita berbeza. Perbezaan tersebut telah dirakam dalam VCD yang berikut:

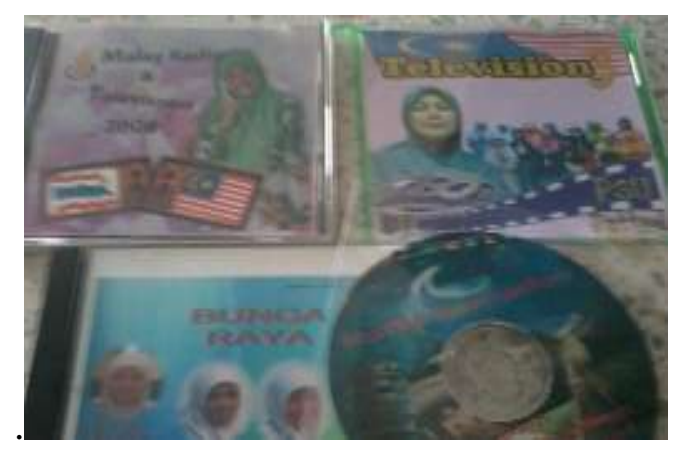

RAJAH 1. CD dan VCD

Perbezaan kedua-duanya jelas memperlihatkan bahawa pemberita hanya melaporkan isu penting sahaja untuk menyampaikan maklumat tentang sesuatu berita, manakala perincian berita dilaporkan oleh pelapor berita atau wartawan. Sekalipun demikian secara struktur ayat, kedua-dua maklumat masih menggunakan laras bahasa sederhana dengan mengambil kira tahap kemampuan pendengar secara umum sehingga bahasa yang digunakan dapat difahami oleh orang awam. Untuk itu cara penyampaian atau laporan hendaklah sesuai dengan intonasi sehingga maklumat yang disampaikan dapat difahami oleh pendengar.

\section{Faedah dan Percaya Diri}

Selepas mengikuti mata kuliah ini, didapati para pelajar lebih yakin diri dan berjaya menggunakan bahasa Melayu persuratan dengan lebih berkesan, menepati maksud penulisan berita dan dapat memperlihatkan bakat sebagai pemberita surat khabar. Hal ini dapat dilihat daripada beberapa contoh hasil latihan industri atau praktikal dua orang mahasiswa yang ditugaskan di Syarikat BERNAMA (Perbadanan Berita Nasional Malaysia) di Kuala Lumpur selama empat bulan.

\section{Beberapa laporan latihan industri dua orang mahasiswa; Kasmenee Bakar dan Wae Masnah Wae Yusoh:}

Latihan industri merupakan keperluan bagi mahasiswa untuk mempraktikkan hal yang telah dipelajari melalui kuliah. Sesi pembelajaran selama tiga tahun enam bulan dalam jurusan Bahasa Melayu peringkat ijazah pertama di PSU merupakan tempoh persediaan asas yang sudah cukup untuk menghadapi dunia pekerjaan yang sebenar dengan realiti pekerjaan dalam bidang berkaitan.

Realiti sebenar kerjaya hanya dapat dirasai apabila seseorang itu pernah terlibat dengan alam pekerjaan yang membabitkan penyesuaian diri dengan sifat pekerjaan yang ditempuhi dan dialami seseorang itu. Pengalaman itu melibatkan emosi, pemikiran dan tingkah laku serta nilai sahsiah seseorang kerana secara jelas ia terlibat dengan persekitaran yang baharu dialaminya. Penglibatan seseorang di dalam alam pekerjaan turut melibatkan sebahagian besar masa dan tumpuan yang perlu diberikan.

Setelah menjalani latihan industri selama empat bulan dari 4 Januari hingga 22 April 2016 di Jabatan Pengarang Meja Berita Am, Bahagian Perkhidmatan Berita Dalam Negeri (PBDN) Bernama, menjadi 
kewajipan kami untuk menyediakan dengan laporan latihan industri bagi memperjelaskan suasana tempat bekerja, fokus sewaktu bekerja, dan pengalaman ketika bekerja menjadi seorang wartawan sepanjang tempoh latihan industri dari mula hingga akhir praktikal.

Sepanjang berada di Jabatan Pengarang Meja Berita Am Bahagian Perkhidmatan Berita Dalam Negeri (PBDN), kami berdua sebagai pelatih telah didedahkan dengan pelbagai maklumat serta mempelajari pelbagai perkara baharu di BERNAMA. Kami juga berpeluang melalui berbagai-bagai jenis pengalaman dengan mengambil setiap peristiwa sebagai pengajaran bagi menimba ilmu dan kemahiran yang bermanfaat serta perlu sebagai seorang wartawan.

Kami berdua ditugaskan di Jabatan Pengarang Meja Berita Am dan diletakkan sebagai Wartawan Pelatih di bahagian Meja berita Am, Meja Berita Jenayah dan Sukan.

Secara ringkasnya sebagai pelatih, kami sudah mengetahui semua peringkat penghasilan sesebuah cerita ataupun story news yang hendak dikongsikan kepada khalayak umum. Sehubungan perkara itu, kami amat berpuas hati kerana telah diberi peluang berada pada tugasan dalam mahupun tugasan luar. Antara latihan industri yang perlu dijalankan oleh pelajar selama di BERNAMA ialah:

1. Pelatih ditugaskan untuk menghasilkan berita yang berkenaan dengan Bahasa Melayu di Selatan Thailand. Satu daripada tajuk yang telah kami laksanakan ialah 'Generasi Muda di Nakhon Srithamarat Semakin Lupakan Bahasa Melayu’ sebagaimana dalam Rajah 2:

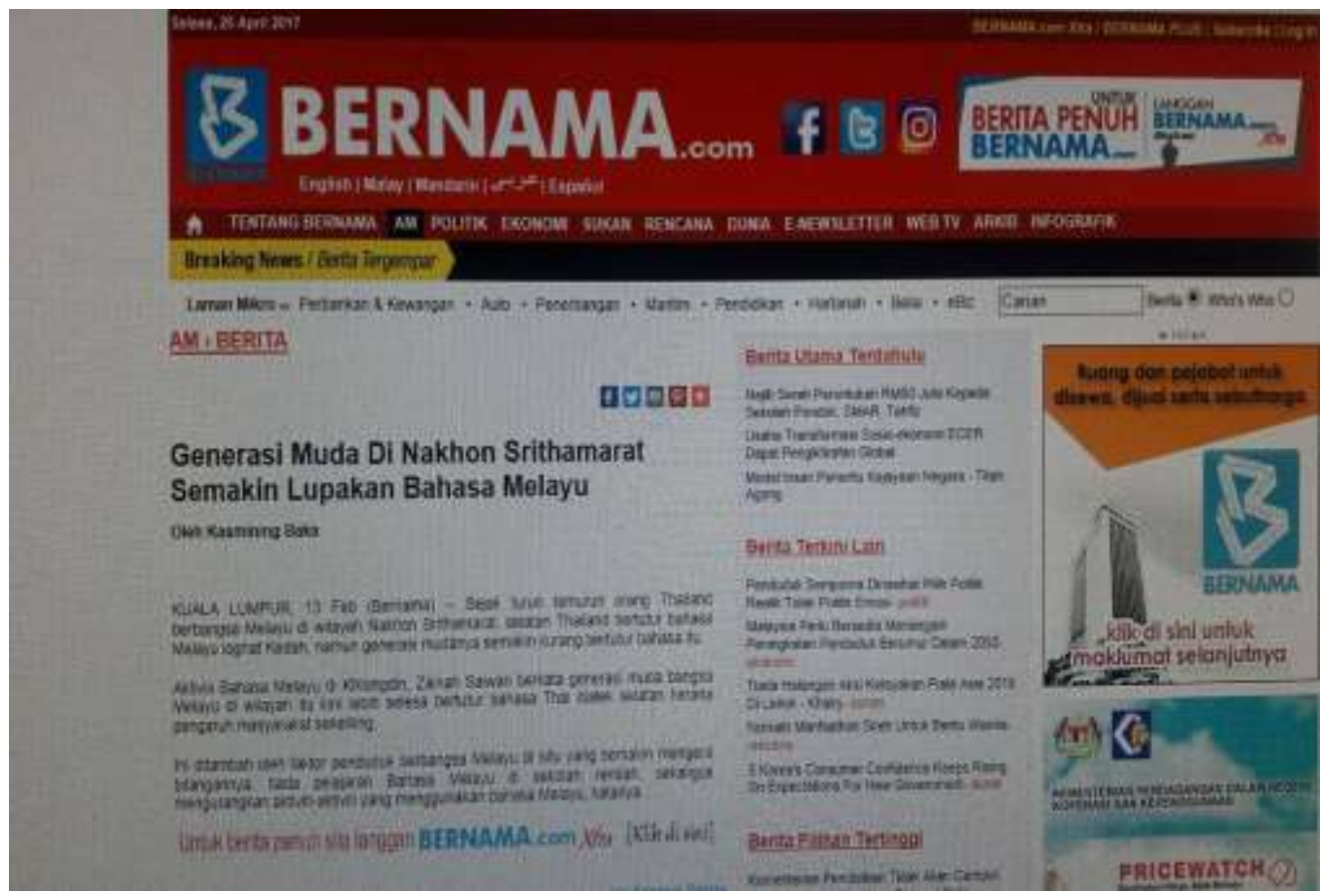

\section{RAJAH 2. Laman sesawang}

BERNAMAhttp://www.bernama.com/bernama/v8/bm/ge/newsgeneral.php?id=1215209

2. Kami juga ada waktu tertentu ditugaskan untuk menemu bual pelajar Thai di Sekolah Menengah Kebangsaan Agama Kuala Lumpur. Tugasan tersebut menghasilkan sebuah berita mengenai para pelajar yang terlibat. Tulisan semi berita yang telah kami hasilkan ekoran daripada wawancara tersebut ialah 'Kelemahan Bahasa Melayu, Tidak Patah Semangat Pelajar Thai untuk Berjaya' sebagaimana Rajah 3: 


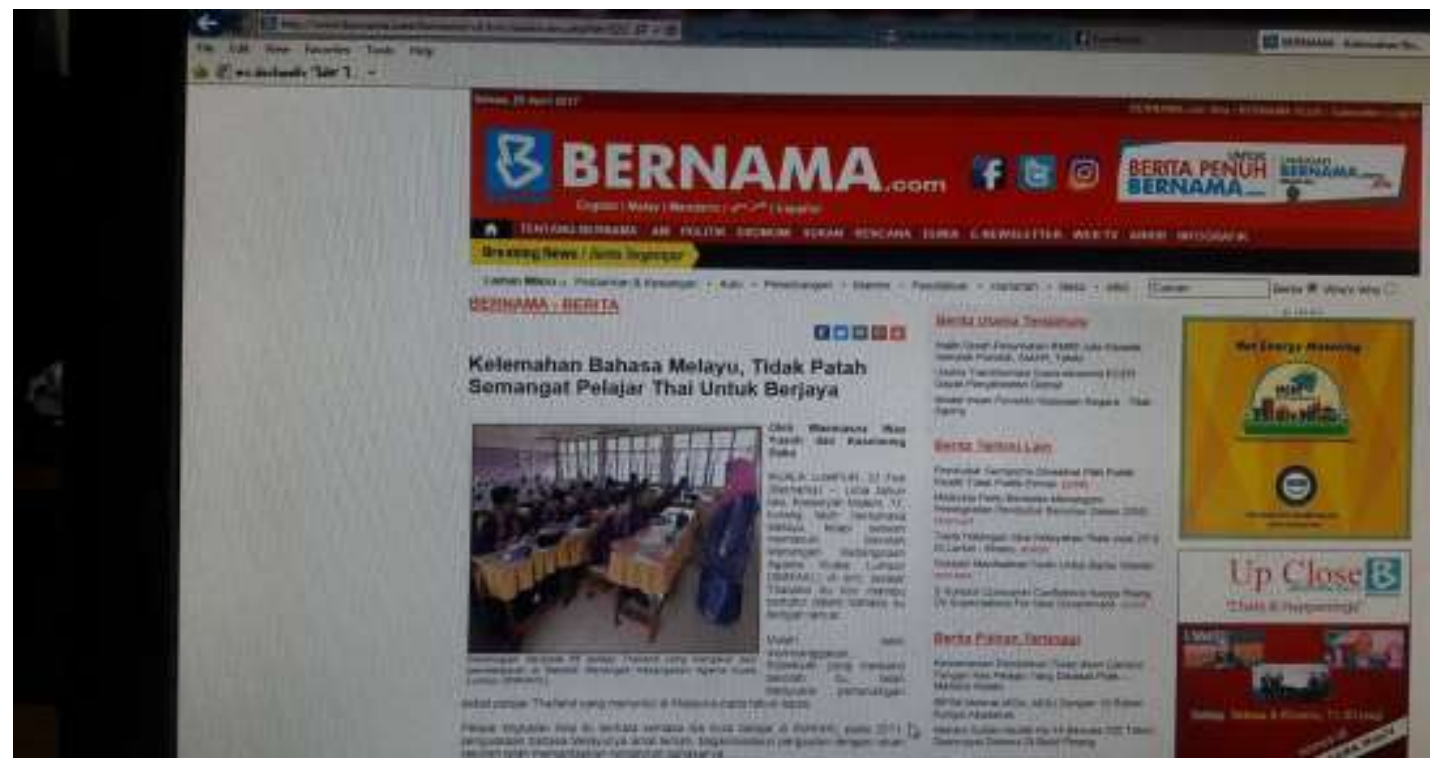

RAJAH 3. Laman Sesawang BERNAMA

http://www.bernama.com/bernama/v8/bm/newsindex.php?id=1217808

3. Pelatih ditugaskan untuk menghasilkan berita-berita yang berkaitan dengan Negara Thailand. Satu daripadanya ialah tulisan mengenai rakyat Thai yang bekerja di kedai Tomyam di sekitar Kuala Lumpur, di samping membuat tinjauan ke atas pendatang asing warga Thailand yang bekerja sebagai tukang masak, pekerja am dan yang membuka restoran di sekitar kota raya itu.

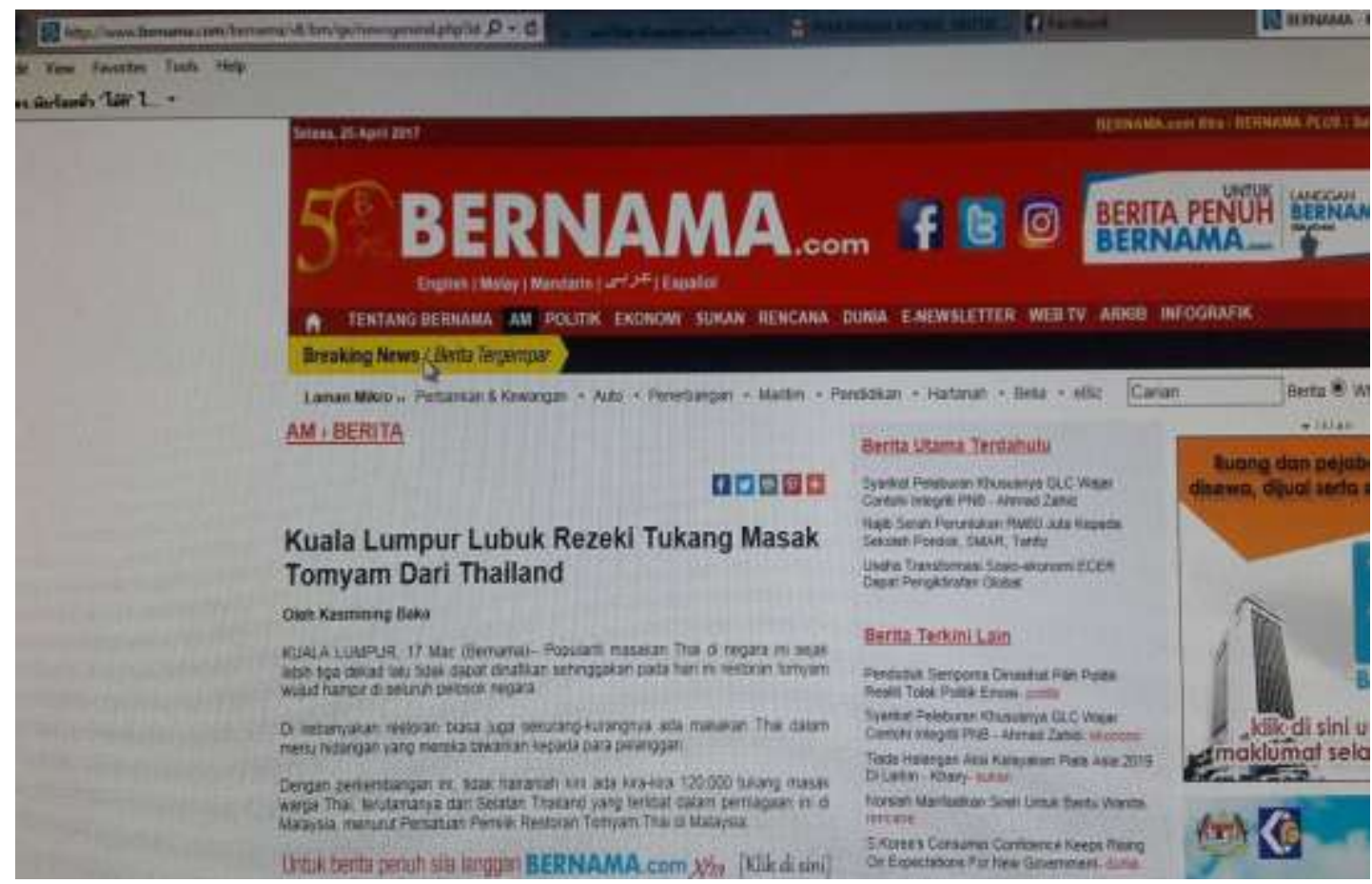

RAJAH 4. Laman Sesawang BERNAMA

http://www.bernama.com/bernama/v8/bm/ge/newsgeneral.php?id=1225869 
4. Kami ditugaskan keluar ke lapangan membuat liputan berita dalam majlis "Simposium Bahasa dan Kebudayaan" sempena program "Ekspresi Puisi Dunia Numera 2016" di Dewan Bahasa dan Pustaka Kuala Lumpur. Tajuk yang telah kami hasilkan (tulisan Kasmenee Bakar) seperti berikut:

\begin{tabular}{|c|c|c|c|c|c|c|c|c|}
\hline $\begin{array}{l}\text { astro } \\
\text { AWANI }\end{array}$ & BERTIA & Foro & VIDEO & LIVE TV & RANCANGAN & INFOGRAFIK & APPS & LAOLL.. \\
\hline MaLAYsia & DUMIA & nuswes & SUKAN & HIIUURAN & TEKNOLOCI & GAYA HIDUP & POLTIK & PERSPEKTIF \\
\hline
\end{tabular}

\section{DBP bimbang penulis muda terpengaruh karya 'indie'}

Dernama | tom Mac 20, 2016 07:43 MYT

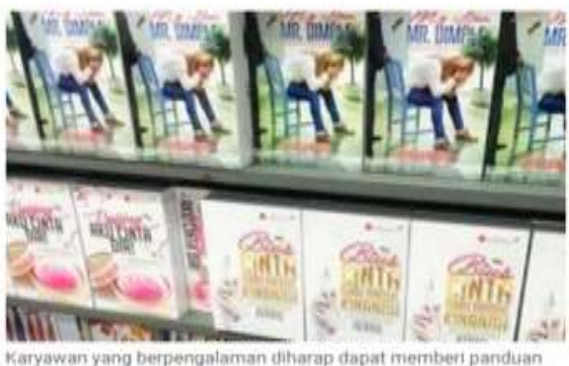

Karyawan yang berpengalaman diharap dapat membeti panduan dan teguran kepada generasil mudis berhubung keasauaian bahasis yang mereka gunakan - Foto Twitto

menghiraukan bahasa dan akal budi yang sebenar," katanya selepas merasmikan Simposium Bahasa dan Kebudayaan sempena program Ekspresi Puisi Dunia Numera (EPDN) 2016 di sini, Sabtu. menyambut baik kemunculan ramai penulis muda kerana ada antara mereka terpengaruh dengan karya 'indie'.

Pengerusi Lembaga Pengelola DBP Datuk Seri Md Salleh Yaapar berkata kecenderungan terhadap karya 'indie' boleh merosakkan bahasa Melayu dan jati diri bangsa Melayu.

\section{*...ada yang menggelarkan diri mereka sebagai} penulis 'indie' dengan penerbitan 'indie' yang tidak
KUALA LUMPUR: Dewan Bahasa dan Pustaka (DBP) namun, perkembangan sihat itu dilihat boleh terjejas

RAJAH 5. Laman Sesawang ASTRO

http://www.astroawani.com/berita-hiburan/dbp-bimbang-penulis-muda-terpengaruh-karya-indie-99160

5. Kami juga mendapat kesempatan untuk menulis di mass-media Cetak Utusan Melayu dan Sinar Harian seperti keratin yang berikut:

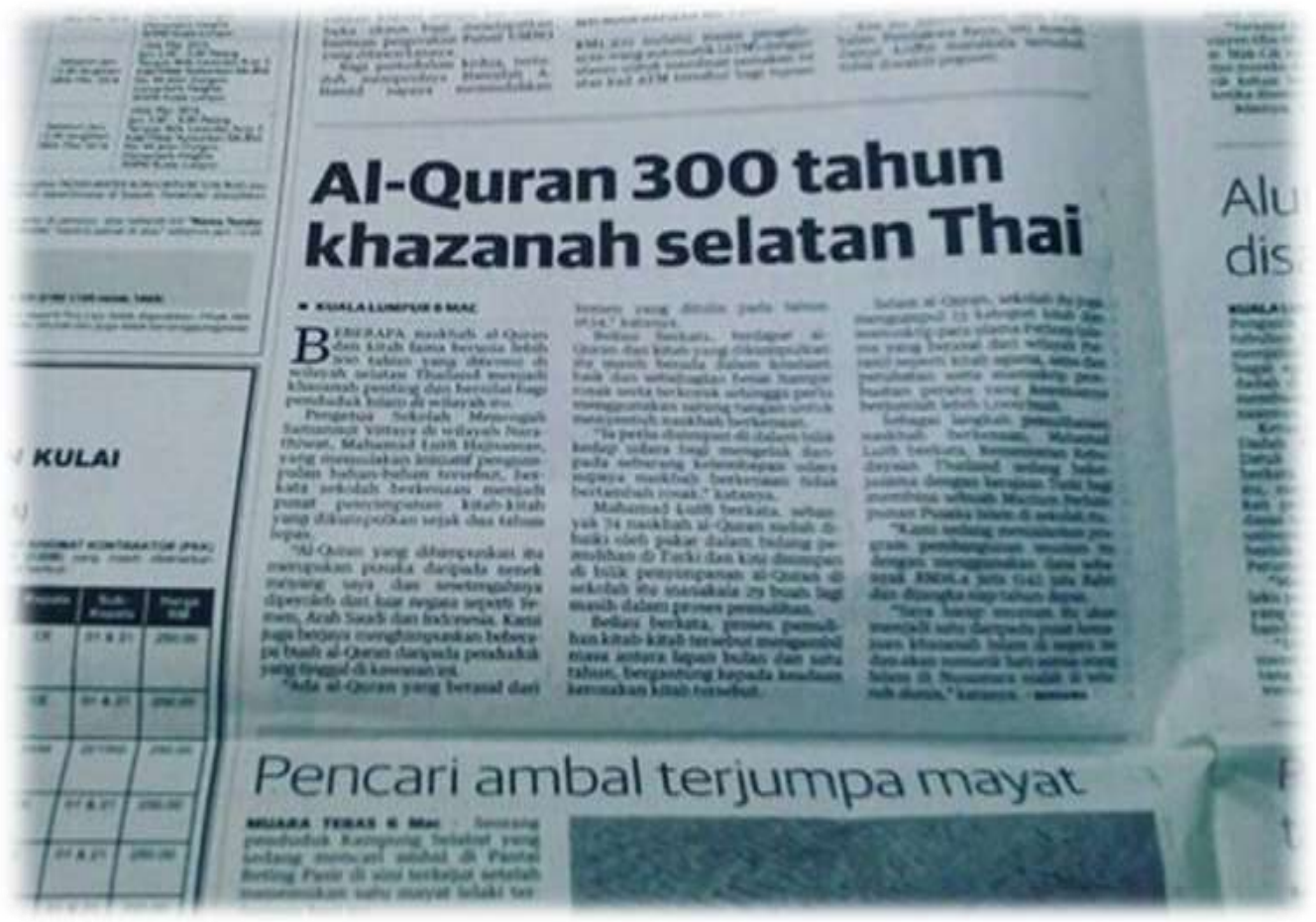

RAJAH 6. Akhbar “Utusan Malaysia”, tanggal 7 Mac 2016, halaman 26 


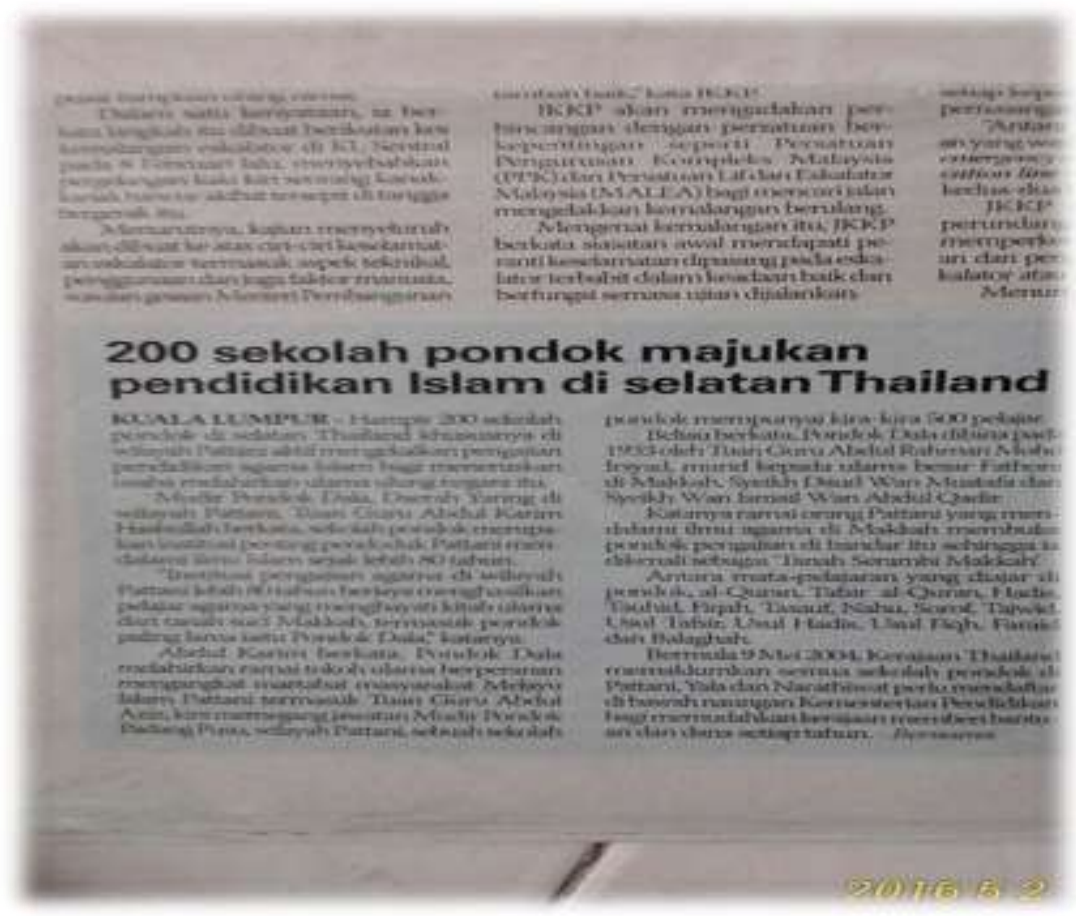

RAJAH 7. Akhbar Sinar Harian tanggal 15 Februari 2016, halaman 10

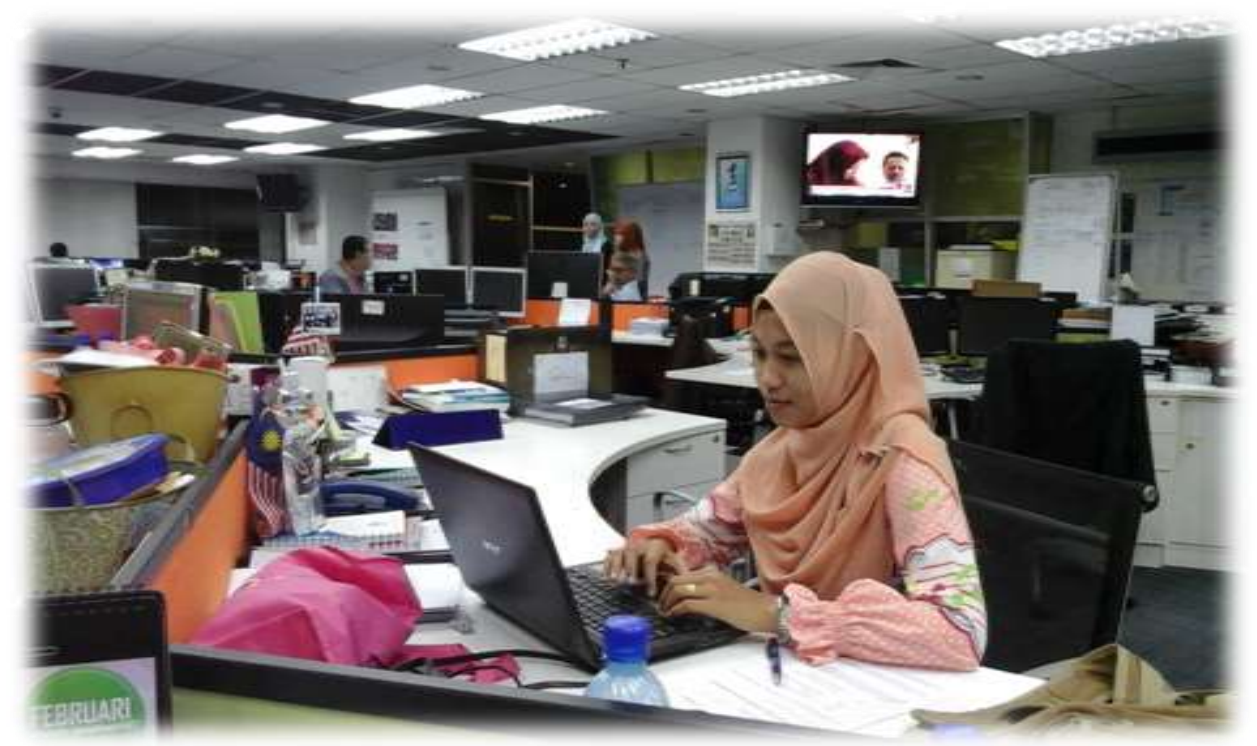

RAJAH 8. Kasmenee Bakar ketika menjalani latihan di BERNAMA 


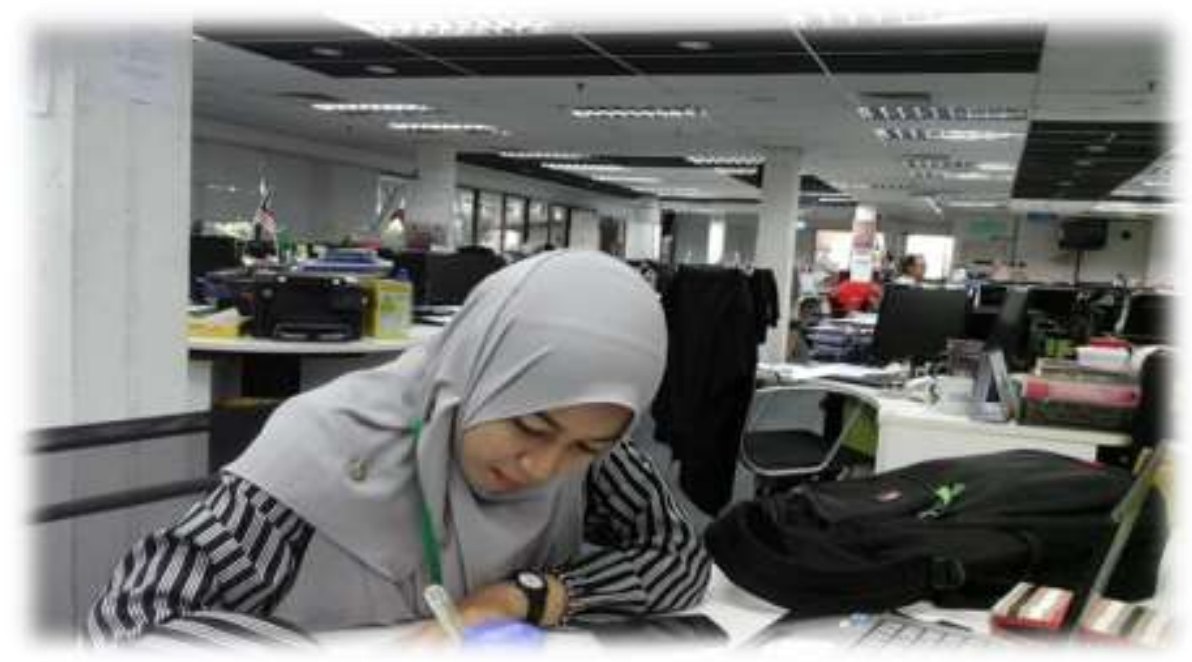

RAJAH 9. Wea Masnah ketika menjalani latihan di BERNAMA

\section{KESIMPULAN}

Kajian ini memberi implikasi terhadap proses pengajaran dan pembelajaran mass-media bahasa Melayu di IPTA Thailand, khasnya di PSU, kampus Pattani. Kurikulum yang berasaskan teknologi maklumat pada hari ini seolah-olah membuka peluang kepada pensyarah dan para mahasiswa untuk memanfaatkannya dengan menggunakan medium CD dan VCD sebagai rakaman. Pensyarah dapat memanfaatkan ilmu yang dimiliki dengan mengkreasikan pelbagai kaedah pengajaran yang sesuai dengan pelajar di IPTA. Pelajar juga mendapat faedah daripada kursus mass-media ini, dan semakin dapat meyakini diri ketika mengikuti latihan industri di pusat berita ternama sepert di Bernama, Kuala Lumpur.

Semakin banyak institusi penyiaran di Thailand, khasnya di Pattani semakin memberi peluang kepada para siswazah untuk mendapatkan kerjaya. Salah satu kerjaya yang sesuai dengan kemahiran mereka selepas mengikuti kuliah mass-media ini antaranya sebagai juruhebah dan pembaca berita di stesyen radio Media Selatan, dan So-O-Bo-To. Selain daripada itu, ada graduan yang terlibat dalam kerjaya sebagai pemberita untuk televisyen berbahasa Thai di Thailand.

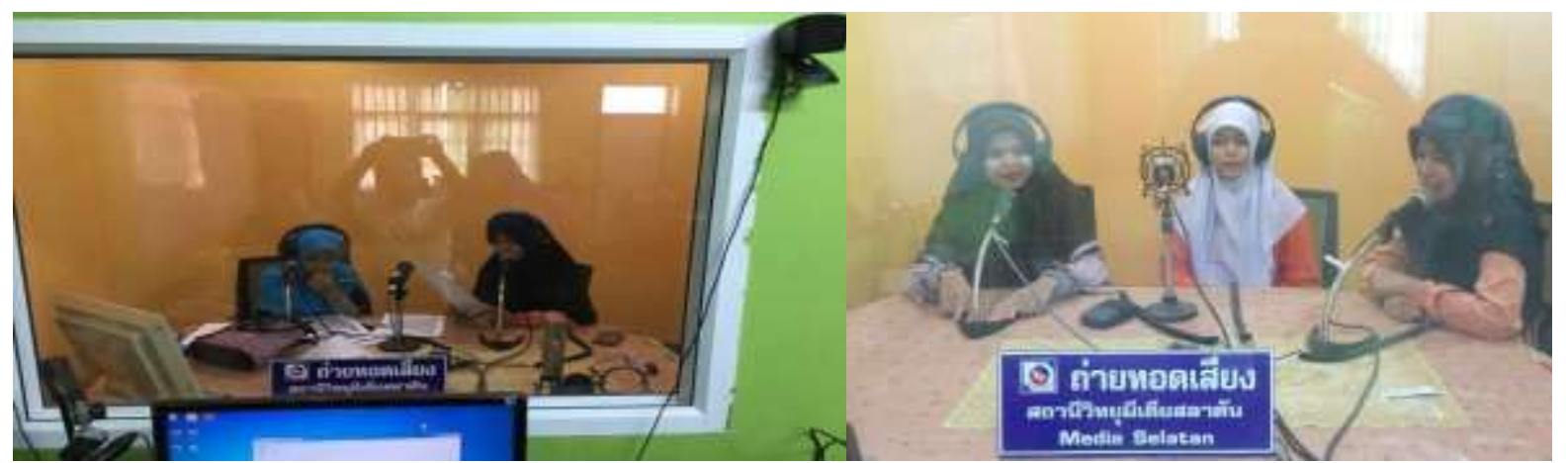

RAJAH 9. Wea Masnah Wan Yusoh dan Fatihah Sabuding sebagai juruhebah radio di Media Selatan 


\section{RUJUKAN}

Ab. Razak Ab. Karim \& Mhd. Saiful Haq bin Hussin. (2011). Tahap penguasaan bahasa Melayu pelajar di Islamik Santitham Foundation School. Jurnal Pengajian Melayu Universiti Malaya, Vol. 22, 18- 44.

Alizah Lambri \& Zamri Mahamod. (2015). Pelaksanaan aktiviti pembelajaran berasaskan masalah dalam proses pengajaran dan pembelajaran bahasa Melayu. Pendeta: Jurnal Bahasa dan Sastera Melayu, Vol. 6, Issue 1, 98-117.

Djusmalinar. (2013). Praktikal bahasa: Pembelajaran bahasa Melayu di IPT Selatan Thailand. Artikulasi: Jurnal Kajian Bahasa dan Sastra Indonesia, Vol. 12, No.1, 106-114.

Mohd. Majid Konting. (2009). Penyelidikan Pendidikan. Kuala Lumpur: Dewan Bahasa dan Pustaka.

Moleong, Lexy. (2007). Metodologi Penelitian Kualitatif. Bandung: Remaja Rosda Karya.

Norul Haida Rezuan. (2012). Pembelajaran secara koperatif dalam kelas bahasa Melayu. Pendeta: Jurnal Bahasa dan Sastera Melayu, Vol. 3, Issue 1, 52-70. 